RENAN TELES CAMPOS DE CARVALHO

\title{
JUSTIÇA INTERNACIONAL DO RECONHECIMENTO E A JURISPRUDÊNCIA DA CORTE INTERAMERICANA DE DIREITOS HUMANOS
}

Dissertação de Mestrado

Orientadora: Prof. ${ }^{a}$ Associada Dr. ${ }^{a}$ Cláudia Perrone-Moisés

UNIVERSIDADE DE SÃO PAULO

FACULDADE DE DIREITO

SÃO PAULO - SP

2019 


\title{
JUSTIÇA INTERNACIONAL DO RECONHECIMENTO E A JURISPRUDÊNCIA DA CORTE INTERAMERICANA DE DIREITOS HUMANOS
}

Dissertação apresentada à Banca Examinadora do Programa de PósGraduação em Direito, da Faculdade de Direito da Universidade de São Paulo, como requisito parcial para a obtenção do título de mestre em Direito, na área de concentração Direito Internacional, sob orientação da Prof. ${ }^{a}$ Associada Dr. ${ }^{a}$ Cláudia Perrone-Moisés.

\author{
UNIVERSIDADE DE SÃO PAULO \\ FACULDADE DE DIREITO \\ SÃO PAULO - SP


Serviço de Processos Técnicos da Biblioteca da

Faculdade de Direito da Universidade de São Paulo

Carvalho, Renan Teles Campos

Justiça internacional do reconhecimento

e a jurisprudência da Corte Interamericana de Direitos Humanos / Renan Teles Campos de Carvalho. - São Paulo: R. T. C. Carvalho, 2019. $127 \mathrm{f}$.

Dissertação (Mestrado) - Universidade de São Paulo, 2019.

Orientador: Profa. Associada Dra. Cláudia Perrone-Moisés

Notas de rodapé.

Inclui bibliografia

1. Corte Interamericana. 2. Justiça internacional. 3. Reconhecimento. 4. Vítima.

5. Vulnerabilidade. I. Perrone-Moisés, Cláudia. II. Título. 
NOME: RENAN TELES CAMPOS DE CARVALHO

TÍTULO: JUSTIÇA INTERNACIONAL DO RECONHECIMENTO E A JURISPRUDÊNCIA DA CORTE INTERAMERICANA DE DIREITOS HUMANOS

Dissertação apresentada à Banca Examinadora do Programa de PósGraduação em Direito, da Faculdade de Direito da Universidade de São Paulo, como requisito parcial para a obtenção do título de mestre em Direito.

Orientadora: Prof. ${ }^{a}$ Associada Dr. ${ }^{a}$ Cláudia Perrone-Moisés. 
Sur une barricade, au milieu des pavés Souillés d'un sang coupable et d'un sang pur lavés,

Un enfant de douze ans est pris avec des hommes.

- Es-tu de ceux-là, toi ? - L'enfant dit : Nous en sommes.

- C'est bon, dit l'officier, on va te fusiller.

Attends ton tour. - L'enfant voit des éclairs briller,

Et tous ses compagnons tomber sous la muraille.

Il dit à l'officier : Permettez-vous que j'aille Rapporter cette montre à ma mère chez nous?

- Tu veux t'enfuir? - Je vais revenir. - Ces voyous

Ont peur ! où loges-tu ? - Là, près de la fontaine.

Et je vais revenir, monsieur le capitaine.

- Va-t'en, drôle ! - L'enfant s'en va. - Piège grossier!

Et les soldats riaient avec leur officier,

Et les mourants mêlaient à ce rire leur râle ; Mais le rire cessa, car soudain l'enfant pâle, Brusquement reparu, fier comme Viala, Vint s'adosser au mur et leur dit : Me voilà.

La mort stupide eut honte et l'officier fit grâce.

[...]

(Victor Hugo, "Sur une barricade") 


\section{AGRADECIMENTOS}

Agradeço imensamente a todos que, de qualquer forma, tenham me auxiliado na elaboração da dissertação, em especial à Prof. ${ }^{a}$ Dr. ${ }^{a}$ Cláudia PerroneMoisés que, durante os últimos três anos, entre palavras, gestos e constante exercício de doação, conjugou de forma única o verbo "orientar". Gratidão é palavra que define.

Agradeço à minha família (Mainha, Nai e Anne), porto seguro para as minhas constantes partidas, ausências e retornos.

Quero agradecer ainda à Prof. ${ }^{a}$ Dr ${ }^{\mathrm{a}}$. Kathia Martin-Chenut que me recebeu no Institut des Sciences Juridique et Philosophique de la Sorbonne (ISJPS) para complementar a pesquisa necessária à elaboração da presente dissertação. Também não poderia deixar de agradecer aos Profs. Dr. Guilherme Assis de Almeida e Dr. José Reinaldo Lima Lopes por todos os comentários e as sugestões formulados durante o exame de qualificação.

Aos meus amigos queridos, em especial Leonardo Fernandes e Natália Covale, agradeço pela disponibilidade, independente da hora, para leituras, comentários a respeito do conteúdo do trabalho e conselhos para que eu me mantivesse sereno.

Ao Alc, a quem dedico as palavras, pelo caminhar conjunto. 
CARVALHO, Renan Teles Campos de. Justiça Internacional do Reconhecimento e a jurisprudência da Corte Interamericana de Direitos Humanos. $127 \mathrm{f}$. Dissertação (Mestrado em Direito Internacional) - Faculdade de Direito, Universidade de São Paulo, São Paulo, 2019.

\section{RESUMO}

A presente dissertação tem por objetivo estudar um modelo de justiça internacional que se concretiza no reconhecimento de indivíduos e grupos vulneráveis a partir da análise da jurisprudência da Corte Interamericana de Direitos Humanos que trata do tema. Após expor um conceito doutrinário do Direito Internacional do Reconhecimento, propôs-se a ampliação do seu objeto de estudo a partir da teoria do reconhecimento social, bem como da inter-relação que ela estabelece com as ideias de experiências de injustiças e de justiça nas instituições. Em seguida, com base em decisões da Corte Interamericana, busca-se extrair uma dimensão material daquela lógica de justiça, caracterizada pelo reconhecimento das vulnerabilidades das vítimas, bem como uma dimensão procedimental, concretizada na forma em que a jurisprudência interamericana compreende a participação da vítima, isto é, conferindo repercussões procedimentais em decorrência da verificação da vulnerabilidade. Por fim, trabalhou-se com a ideia de como a própria sentença constitui um ato per se de reconhecimento da vítima vulnerável.

Palavras-chave: Corte Interamericana. Justiça internacional. Reconhecimento. Vítimas. Vulnerabilidade. 
CARVALHO, Renan Teles Campos de. Justice internationale de la reconnaissance et la jurisprudence de la Cour Interaméricaine des Droits de I'Homme. $127 \mathrm{f}$. Mémoire (Master en Droit Internacional). Faculté de Droit de l'Université de São Paulo, São Paulo, 2019.

\section{RÉSUMÉ}

La présente recherche a pour objectif d'étudier sur un modèle de justice internationale qui se concrétise par la reconnaissance des individus et des groupes vulnérables, sur la base de l'analyse de la jurisprudence de la Cour interaméricaine des droits de l'homme, qui traite de ce sujet. Après avoir exposé un concept doctrinal de droit international de la reconnaissance, il a été proposé d'élargir son objet d'analyse du point de vue de la théorie de la reconnaissance, ainsi que de la relation qu'elle établit avec des idées d'expériences d'injustice et de justice dans les institutions. Ensuite, sur la base des décisions de la Cour interaméricaine, extraire une dimension matérielle de cette logique de justice, caractérisée par la reconnaissance des vulnérabilités des victimes; ainsi qu'une dimension procédurale, concrétisée dans la manière dont la jurisprudence interaméricaine comprend la participation de la victime, tout en ayant des répercussions procédurales dues à la vérification de la vulnérabilité. Enfin, nous avons travaillé sur l'idée selon laquelle la sentence interaméricaine constitue un acte per se de reconnaissance de la victime vulnérable.

Mots clés: Cour Interaméricaine. Justice internationale. Reconnaissance. Victimes. Vulnérabilité. 
ÍNDICE DE ABREVIATURAS E SIGLAS

$\begin{array}{ll}\text { CADH } & \text { Convenção Americana sobre Direitos Humanos } \\ \text { CIDH } & \text { Comissão Interamericana de Direitos Humanos } \\ \text { CORTE IDH } & \text { Corte Interamericana de Direitos Humanos } \\ \text { DADDH } & \text { Declaração Americana de Direitos e Deveres do Homem } \\ \text { DIDH } & \text { Direito Internacional dos Direitos Humanos } \\ \text { OEA } & \text { Organização dos Estados Americanos } \\ \text { SIDH } & \text { Sistema Interamericano de Direitos Humanos }\end{array}$




\section{SUMÁRIO}

INTRODUÇÃO

1. A JUSTIÇA INTERNACIONAL DO RECONHECIMENTO SOB O PRISMA DAS INSTITUIÇÕ̃ES

1.1 O DIREITO INTERNACIONAL DO RECONHECIMENTO: CONCEITO E ESPECTRO DE ANÁLISE

1.2 AMPLIAÇÃO DO ALCANCE DO CONCEITO DE DIREITO INTERNACIONAL DO RECONHECIMENTO: A LUTA POR RECONHECIMENTO E A EXPERIÊNCIA DE INJUSTIÇAS

1.3 RECONHECIMENTO E JUSTIÇA NAS INSTITUIÇÕES INTERNACIONAIS

1.4 A INSTITUIÇÃO OBJETO DE ANÁLISE: A CORTE INTERAMERICANA DE DIREITOS HUMANOS (CORTE IDH)

2. A DIMENSÃO MATERIAL DA JUSTIÇA INTERNACIONAL DO RECONHECIMENTO NA JURISPRUDÊNCIA DA CORTE IDH: A VÍTIMA VULNERÁVEL.

2.1 DA FIGURA DA PARTE LESADA DO ARTIGO 63 DA CONVENÇÃO AMERICANA SOBRE DIREITOS HUMANOS AO CONCEITO DE VÍTIMA NA JURISPRUDÊNCIA DA CORTE IDH

2.2 A VULNERABILIDADE NA CORTE IDH COMO VETOR DE PROTEÇÃO: O RECONHECIMENTO DE INDIVÍDUOS E GRUPOS VULNERÁVEIS .................59

2.2.1 Vulnerabilidade, uma aproximação conceitual 60

2.2.2 Quadros de reconhecimento de vulnerabilidades na jurisprudência da Corte IDH

2.3 EFEITOS JURÍDICOS DECORRENTES DO RECONHECIMENTO DAS VULNERABILIDADES .75

3 A DIMENSÃO PROCEDIMENTAL DA JUSTIÇA INTERNACIONAL DO RECONHECIMENTO NA JURISPRUDÊNCIA DA CORTE IDH: A INCLUSÃO E A INDIVIDUALIZAÇÃO NO PROCESSO INTERAMERICANO

3.1 A PROCEDIMENTALIZAÇÃO DO RECONHECIMENTO: APONTAMENTOS INICIAIS

3.2 A REGULAMENTAÇÃO DO PAPEL DA VÍTIMA NO PROCEDIMENTO PERANTE A CORTE IDH: APONTAMENTOS CONTEXTUAIS

3.3 A VULNERABILIDADE COMO ELEMENTO DE REPERCUSSÃO PROCEDIMENTAL

3.4 A SENTENÇA INTERAMERICANA COMO ATO PER SE DE RECONHECIMENTO 103 
CONCLUSÃO

107

REFERÊNCIAS BIBLIOGRÁFICAS

112 


\section{INTRODUÇÃO}

[...] seus corpos foram abandonados em um local desabitado, expostos às ações do tempo e à ação dos animais e poderiam ter permanecido assim durante vários dias, se não fossem encontrados fortuitamente. No presente caso, é evidente que o tratamento que se deu aos restos das vítimas, que eram sagrados para seus deuses e, em particular, para suas mães, constitui para estas um tratamento cruel e desumano ${ }^{1}$.

O excerto acima citado poderia facilmente ter sido extraído da obra de Sófocles que narra o sentimento de injustiça vivenciado por Antígona, cujo grito por respeito às leis naturais foi brutalmente sufocado pelo poder arbitrário de Creonte. Mas, distante temporalmente da literatura, trata-se de trecho de decisão da Corte Interamericana de Direitos Humanos (Corte IDH), no caso Villagrán Morales e outros vs. Guatemala (1999), em que se declarou a responsabilidade do Estado por graves violações aos Direitos Humanos.

No referido caso, o Estado da Guatemala deixou de adotar as providências necessárias para investigar, processar e punir os culpados pela prática de detenções arbitrárias, tortura e execução sumária contra pessoas que se encontravam em situação de rua (dentre elas, adolescentes), perpetradas por agentes estatais como forma de suposto combate à criminalidade. Dentre outros direitos violados, a Corte Interamericana declarou que o Estado negou o direito dos familiares de sepultarem as vítimas, em inobservância às suas "tradições, valores ou crenças e, portanto, intensificou seus sofrimentos"2.

Em uma outra cena, restou violado não apenas o direito à sepultura ou à inviolabilidade da fronteira inerente ao corpo, mas o de ser reconhecido como um sujeito de direito. No caso Fernández Ortega e outros vs. México (2010), a violência infringida à Sra. Ortega, sem qualquer consideração por parte do Estado, importou na declaração de responsabilidade estatal e na construção de argumentos que congregam a violação de direitos, sentimento de injustiça e desrespeito à autonomia. Entendeu a Corte, in verbis:

\footnotetext{
${ }^{1}$ CORTE IDH. Caso Villagrán Morales e outros vs. Guatemala. Sentença de 17 nov. 1999, §174. Disponível em: http://www.corteidh.or.cr/docs/casos/articulos/Seriec_63_esp.pdf. Acesso em: 09 jul. 2017.

2 Ibid., §174.
} 
A Comissão adicionou que uma violência sexual, além de afetar a integridade física, psíquica e moral da vítima, quebra sua dignidade, invade uma das esferas mais íntimas de sua vida, seu espaço físico e sexual e a despoja de sua capacidade de tomar decisões a respeito do seu corpo conforme a sua autonomia. Ademais, a violência sexual na presença de um familiar tem um significado particularmente grave, sendo ainda mais humilhante para a vítima e traumático para ambos ${ }^{3}$.

As breves referências aos casos citados, que narram a crueldade imposta a determinadas pessoas e a ausência de reconhecimento da responsabilidade por parte dos Estados antes das sentenças da Corte IDH, têm o condão de estabelecerem uma linha argumentativa a respeito de determinado modelo de justiça observado na jurisprudência interamericana em matéria de indivíduos e grupos vulneráveis.

A análise parte da hipótese da existência de um conjunto decisório da Corte IDH guiado por um padrão de justiça internacional que se fundamenta na figura do reconhecimento, ou seja, direcionada a garantir, no âmbito do processo interamericano, que a experiência da injustiça ${ }^{4}$ vivenciada por uma vítima vulnerável seja reconhecida, assegurando-lhe o direito negado na esfera estatal. Nesse sentido, coloca-se a seguinte questão para investigação: de qual forma um modelo de justiça centrado na figura do reconhecimento se opera no âmbito da jurisprudência da Corte IDH em matéria de indivíduos e grupos vulneráveis?

Antes de traçar parâmetros para responder à dúvida suscitada, é imperioso fixar, brevemente, algumas das ideias adotadas como premissas do trabalho e que, sem prejuízo de serem retomadas, balizam e circunscrevem a ideia de uma justiça do reconhecimento no âmbito de uma instituição internacional específica, qual seja a Corte IDH.

\footnotetext{
${ }^{3}$ Tradução livre do original: "La Comisión agregó que una violación sexual, además de afectar la integridad física, psíquica y moral de la víctima, quebranta su dignidad, invade una de las esferas más íntimas de su vida, su espacio físico y sexual y la despoja de su capacidad para tomar decisiones respecto de su cuerpo conforme a su autonomía. Además, la violación sexual en presencia de un familiar, tiene un significado particularmente grave, siendo aún más humillante para la víctima y traumático para ambos". CORTE IDH. Caso Fernández Ortega vs. México. Sentença de 30 de agosto de 2010, §. 32. Disponível em: http://www.corteidh.or.cr/docs/casos/articulos/seriec_215_esp.pdf. Acesso em: 30 nov. 2016.

${ }^{4} \mathrm{O}$ conceito de experiência de injustiça será trabalhado no item 1.2 do Capítulo 1 . Mas, desde já, adota-se definição preliminar que o compreende como o sentimento de injustiça vivenciado pela não aplicação de princípios instituídos de justiça, a aplicação restrita deles como forma de negar direitos ou quando questiona os próprios princípios, por simplesmente espelharem injustiças institucionais.
} 
A primeira reside no fato desta dissertação não ter por pretensão se debruçar na investigação a respeito do percurso filosófico do termo reconhecimento ${ }^{5}$ como estrutura de investigação apta a justificar uma possível teoria da justiça ${ }^{6}$. Assumindo os riscos que tal escolha carrega, o reconhecimento ${ }^{7}$ é aqui pensando como conceito chave para se compreender a constituição do indivíduo em sujeito de direito, garantindo-lhe, dentro de esferas institucionais, a concretização da sua autonomia.

Com essa ideia, introduz-se como segunda premissa a constatação de o conceito de justiça, de caráter normativo, acompanhar múltiplas descrições ${ }^{8}$. Mas, por coerência, adota-se preliminarmente, na linha do defendido por Axel Honneth, que a noção de justo significa "[...] o que, nas práticas e instituições da sociedade, tende a realizar os valores que são aceitos como gerais em cada uma delas"9, o que na obra dele conflui para a justiça enquanto concretização da liberdade.

Por último, a importância de se compreender que o presente trabalho se insere no campo de estudos do Direito Internacional dos Direitos Humanos (DIDH), o que, por si só, afasta qualquer pretensão de dissertar a respeito de uma teoria da justiça para o Direito Internacional Público, limitando-se a escrever a respeito da existência de uma justiça internacional do reconhecimento descrita na jurisprudência da Corte Interamericana de Direitos Humanos (Corte IDH).

Com isso, não se nega, obviamente, a necessária conciliação entre a problemática do DIDH e do sistema do Direito Internacional Público, razão pela

\footnotetext{
${ }^{5}$ Cf. RICOEUR, Paul. Percurso do reconhecimento. São Paulo: Edições Loyola, 2006.

${ }^{6} \mathrm{O}$ modelo de justiça, aqui analisado, será guiado pela narrativa teórica de autores que trabalham com o tema reconhecimento, tais como Paul Ricoeur, Axel Honneth e Nancy Fraser, observandose os limites e as extensões que conferem à concepção do "reconhecimento". Não se desconhece a ocorrência de divergências entre eles, que serão pontuadas e esclarecidas durante o texto, naquilo que for relacionado ao objeto da investigação.

${ }^{7} \mathrm{O}$ tema será melhor trabalhado no Capítulo 1.

8 "Todas as definições de Justiça aqui apresentadas não são, de fato, definições e sim juízos normativos, sob a capa verbal de definições, tendo como finalidade gerar uma eficácia retórica. Por esse motivo, afirmações como 'a Justiça significa igualitarismo' devem ser interpretadas, não como uma definição do conceito de Justiça, mas como expressão do princípio normativo de que as normas igualitárias de distribuição são justas e as não-igualitárias injustas, de onde se concluiria que apenas as normas do primeiro tipo deveriam ser aprovadas e aplicadas. A melhor coisa é considerar a Justiça como noção ética fundamental e não determinada". BOBBIO, N.; MATTEUCCI, N.; PASQUINO, G. Dicionário de política. Brasília: Editora Universidade de Brasília, v. 1, 1998, p. 661. ${ }^{9}$ HONNETH, Axel. O Direito da Liberdade. São Paulo: Martins Fontes, 2015, p. 32.
} 
qual, como aponta Mazzeschi ${ }^{10}$, refuta-se, de antemão, qualquer alegação de superioridade normativa ou, ainda, a desconsideração do impacto dos Direitos Humanos para a teoria geral do Direito Internacional, por aquele introduzir um germe de subversão na lógica soberanista e nos institutos tradicionais da disciplina.

Feitas as referidas ponderações prévias, constrói-se, assim, a presente dissertação em três capítulos.

No primeiro capítulo, identifica-se, a partir das leituras dos textos de E. Jouannet ${ }^{11}$, o conceito e a extensão do Direito Internacional do Reconhecimento. Por meio de uma revisão bibliográfica, propõe-se pensá-lo sob o prisma da luta por reconhecimento e sentimento de injustiça, ampliando seu campo de incidência e justificando o porquê de uma análise de casos que lidam com indivíduos e grupos vulneráveis na jurisprudência da Corte Interamericana.

Nesse sentido, utiliza-se da teoria do reconhecimento social, alicerçada no pensamento de $A$. Honneth ${ }^{12}$, em que o ato de reconhecer se afigura como elemento constitutivo do sujeito de direito, garantindo-lhe a autonomia necessária para adquirir e exercer direitos. E, como forma de incluir um substrato de verificação empírica, aglutina-se ao debate a noção de experiência de injustiças, trabalhada por $\mathrm{E}$. Renault ${ }^{13}$, visto a potencialidade que possui para gerar um sentimento de ação direcionado a uma luta por justiça. Ainda no capítulo inaugural, salienta-se que, não é possível pensar justiça do reconhecimento distante de espaços institucionais, oportunidade em que se apresenta a engenharia institucional objeto de estudo, qual seja a Corte IDH.

A partir de então, com o escopo de sistematizar e responder à problemática estabelecida, opta-se por uma divisão entre uma dimensão material da justiça do reconhecimento, centrada na construção jurisprudencial interamericana acerca da vítima vulnerável (Capítulo 2), bem como uma dimensão processual, na qual se investiga a forma em que a Corte IDH inclui e individualiza aquela vítima no processo interamericano (Capítulo 3).

\footnotetext{
${ }^{10}$ MAZZESCHI, Riccardo Pisillo. Responsabilité de L'état Pour Violation Des Obligations Positives Relatives Aux Droits de L'homme. Recueil des Cours de l'Académie de Droit International, v. 333, 2008.

11 JOUANNET, Emmanuelle. Qu'est-ce qu'une société internationale juste? Le droit international entre développement et reconnaissance. Paris: Pedone, 2011.

${ }^{12}$ HONNETH, Axel. Luta por reconhecimento: a gramática moral dos conflitos sociais. São Paulo: Editora 34, 2003.

${ }^{13}$ RENAULT, Emmanuel. L'expérience de l'injustice: essai sur la théorie de la reconnaissance. Paris: La Découverte, 2017.
} 
Desse modo, no segundo capítulo, após investigar a inclusão da vítima na linguagem do Direito Internacional dos Direitos Humanos, apresenta-se o significado que a jurisprudência da Corte IDH Ihe confere, bem como se disserta, a partir dos casos escolhidos, a respeito dos quadros de vulnerabilidade trabalhados nas sentenças interamericanas.

Por outro lado, por interessar não apenas o estudo acerca do conceito de vulnerabilidade construído pela Corte, propõe-se examinar se daquele se extraem repercussões jurídicas. Ou seja, mostra-se imperioso pesquisar se nas demandas envolvendo vulneráveis, os juízes interamericanos determinam a adoção de medidas especiais de proteção a serem observadas pelo Estado demandado.

E, por sua vez, no terceiro capítulo, disserta-se a respeito de como o processo interamericano reflete o reconhecimento da vítima vulnerável, ocasião em que se debaterá se o modelo procedimental adotado, pela Corte IDH, reflete as ideias de inclusão e especificidade dos indivíduos e grupos vulneráveis. Assim, no último capítulo, a investigação recai na verificação dos eventuais efeitos que o reconhecimento da vítima vulnerável gera para o processo interamericano.

Além de traçar um breve itinerário da estruturação do presente trabalho, entende-se que é importante trazer algumas considerações a propósito da metodologia utilizada na abordagem da jurisprudência interamericana. Isto porque o substrato de análise que deu origem à presente dissertação é integrado por um referencial teórico ${ }^{14}$ e um acervo jurisprudencial, especificamente as decisões da Corte IDH que tratam de indivíduos e grupos vulneráveis.

É importante pontuar que, até agosto de 2018, a Corte resolveu 235 (duzentos e trinta e cinco) $\operatorname{casos}^{15}$ e exarou 25 (vinte e cinco) opiniões consultivas.

\footnotetext{
${ }^{14}$ Apesar de não se tratar de uma tese, aqui plenamente aplicáveis as observações que François Ost realiza no tocante à construção das teses de doutorado em Direito, principalmente das dificuldades de manejo de um conjunto doutrinário marcado pela heterogeneidade dos atores que $o$ constrói, a sobrecarga de informações (dissonante e que leva a caminhos distintos) e a velocidade em que é colocado e questionado. Cf. OST, François. A tese de doutorado em Direito: do projeto à defesa. Revista de Estudos Constitucionais, Hermenêutica e Teoria do Direito (RECHTD), maio-ago. $2015 . \quad$ Disponível em: http://revistas.unisinos.br/index.php/RECHTD/article/view/rechtd.2015.72.01/4718. Acesso em: 05 de jul. 2017.

15 O quantitativo foi encontrado utilizando os dados extraídos do Relatório Anual (2017) com a contagem individual no sítio eletrônico até agosto de 2018. Cf. CORTE IDH. Relatório Anual da Corte Interamericana de Direitos Humanos (2017), 2018, p. 65. Disponível em: http://www.corteidh.or.cr/tablas/informe2017/portugues.pdf. Acesso em: 06 out. 2018.
} 
E, desse universo, optou-se pelo exame de 35 (trinta e cinco) decisões que tratam, direta ou indiretamente, do que leituras prévias da doutrina identificaram como indivíduos e grupos vulneráveis (crianças, mulheres, migrantes, pessoas portadoras de deficiência, pessoas submetidas à detenção, comunidades originárias, dentre outros). $\mathrm{E}$, dada a pertinência que guardam com o tema e o aporte conceitual que carregam, foram analisadas 4 (quatro) opiniões consultivas.

Logo, desde já, expõe-se que o estudo primordial recairá na atuação contenciosa da Corte Interamericana e, especificamente, nas sentenças de mérito. Portanto, ainda que pudessem guardar pertinência com os temas aqui tratados, não foram objetos de investigação: (i) as decisões tomadas no âmbito das medidas provisórias e as decorrentes de interpretação sobre as sentenças de mérito; (ii) as resoluções na fase de supervisão de cumprimento de sentença; (iii) os votos em separados dos Juízes, em que pese, algumas vezes serem mencionados no texto, dada a pertinência que estabelecem no esclarecimento e na extensão das sentenças de mérito ${ }^{16}$.

Conforme referido, a partir de estudo doutrinário antecedente, houve um processo de identificação prévia dos casos sob os quais a Corte IDH se debruçou ao lidar com o tema das vulnerabilidades. Isto porque o sistema de "buscador de jurisprudência" no sítio eletrônico da Corte Interamericana é incipiente quanto à pesquisa de palavras-chaves, razão pela qual um mapeamento completo a respeito de todas as sentenças em que eventualmente possa ter sido reconhecida uma vítima vulnerável dependeria da leitura de todos os atos decisórios até então produzidos.

Porém, compreende-se que o recorte jurisprudencial realizado se mostra adequado para a investigação do tema, seja pela ausência de uma pretensão quantitativa, bem como pela própria estrutura em que a Corte IDH constrói suas decisões, observando-se um sistema de precedente, o que permitiu a leitura de sentenças correlatas, quando pertinentes a elucidar a indagação posta para estudo.

Por fim, antes de adentrar nos capítulos, outro ponto que se deve salientar consiste na circunstância das sentenças interamericanas terem sido exaradas sob a vigência de regulamentos diversos, que tende a impactar, entre

${ }^{16}$ Cf. RIVIĖRE, Florence. Les opinions séparées des juges à la Cour Européenne des Droits de l'Homme. Bruxelas: Bruylant, 2005, 464 p. 
outras questões, o papel da vítima no processo. Dessa forma, quando verificadas divergências jurisprudenciais decorrentes de tal alteração, privilegiaram-se os entendimentos mais recentes da Corte IDH. 


\section{CONCLUSÃO}

Diante do dissertado, pode-se visualizar que há um enorme caminho a trilhar: prático e teórico. Sabe-se que, tal constatação apesar de trivial é necessária de ser reafirmada, quando se tem claro que o Direito Internacional dos Direitos Humanos se submete a "(...) uma história que não está terminada e que continua a ser escrita hoje"1.

Conforme se observou no presente trabalho, apesar da ausência de subjetividade internacional do indivíduo, a Corte IDH ao colocá-lo como destinatário ${ }^{2}$ final dos direitos inscritos na $\mathrm{CADH}$, por intermédio da ressignificação do papel processual da vítima, constrói um Sistema Interamericano de caráter mais protetivo. Não por outra razão, ao longo das décadas, verificaram-se profundas reformas dos regulamentos, bem como a criação de mecanismos materiais de assistência e de concretização de um adequado processo legal direcionado à substancialização do acesso à justiça, tais como a instituição do fundo de apoio às vítimas $^{3} \mathrm{ou}$, ainda, quando estabelecida a figura do Defensor Interamericano.

Independente da dificuldade executória dos seus julgados, cuja resistência é uma constante nas ordens internas, a Corte IDH ocupa um local de protagonismo no sistema regional de proteção dos Direitos Humanos. Os seus julgados representam não somente um ato de reconhecimento em prol da vítima que teve os seus direitos violados, mas tornam visíveis, para todos os jurisdicionados, o conteúdo e a extensão dos direitos e deveres previstos na CADH e nos demais instrumentos normativos.

Com isso, de maneira constante, alerta-se ao Estado dos deveres assumidos com a comunidade internacional, bem como torna possível a mobilização social em torno de pautas jurídicas por ela definidas. Portanto, a Corte

\footnotetext{
1 Tradução livre do original: “(...) une histoire qui n'est pas achevée et qui continue à s'écrire aujourd'hui'. LOCHAK, Danièle. Les droits de I'homme. Paris: La Découverte, 2005, p. 06. (Collection Repères).

${ }^{2}$ Não se desconhece as infindáveis discussões a propósito da existência de uma subjetividade internacional da pessoa humana. Cf. MAZZESCHI, Riccardo Pisillo. Responsabilité de L'état Pour Violation Des Obligations Positives Relatives Aux Droits de L'homme. Recueil des Cours de l'Académie de Droit International, v. 333, 2008.

${ }^{3}$ OEA. Regulamento da Corte Interamericana de Direitos Humanos sobre o funcionamento do fundo de assistência jurídica às vítimas. Disponível em: https://www.oas.org/pt/cidh/mandato/Basicos/asistenciaCorte.pdf. Acesso em: 20 nov. 2018.
} 
Interamericana ao criar a norma convencional interamericana exerce um poder 4 capaz de instigar a transformação das ordens internas. Ela não apenas reafirma direitos, violados na órbita estatal, como, por intermédio de sua atividade jurisdicional, mostra-se capaz de satisfazer demandas por justiça.

A Corte IDH tem exercido uma criativa atividade interpretativa, ressignificando direitos consolidados no texto convencional, permitindo, a partir disto, uma abertura da ordem jurídica interamericana às reinvindicações por justiça formuladas pelas vítimas que veem suas pretensões obstadas, desconsideradas ou limitadas pelo direito estatal. A sentença interamericana funciona assim como instrumento de condição e consequência de e para um ato de justiça.

Porém, apesar de toda essa potencialidade, que, na presente dissertação, foi constatada quando da investigação de uma dimensão material da justiça internacional do reconhecimento (Capítulo 2), é imprescindível que se confiram maiores efeitos protetivos quando no caso estiverem em disputa direitos de vítimas claramente vulneráveis. Não se trata, apenas, de clamor teórico, mas da constatação da vulnerabilidade decorrer, antes de tudo, do esquecimento e da invisibilidade social infligidas a determinados indivíduos e grupos.

O fato de figurarem como primeiras vítimas, mas últimos a serem reparados (quando um ato de justiça chega a ser praticado), exige um esforço coletivo, consciente e estruturado de ação. A vítima vulnerável não carrega apenas a privação do direito, mas é submetida às estruturas mais injustas, que se entranham no âmbito institucional e são perpetuadas no tempo histórico dos países latino-americanos.

Não por outra razão, considerando as especificidades das violações cometidas contra os referidos sujeitos, os juízes interamericanos têm consciência da insuficiência de critérios tradicionais de desigualdade ou de simples fragilidade. É, nesse sentido, que a jurisprudência interamericana começa a trabalhar com definições de violações perpetradas no âmbito de contextos de discriminação estrutural, ao passo em que reforça a ideia de vulnerabilidade cumulativa, visto ambos os conceitos permitirem, de certa forma, uma compreensão conglobante das demandas que lhe são submetidas.

${ }^{4}$ Cf. SCHAHMANECHE, Aurélia. La Cour européenne des droits de l'homme, nouveau pouvoir, $p$. 33-56. In: CAIRE, Anne-Blandine (Coord.). Les nouveaux pouvoirs: approche pluraliste des foyers de création du droit. Belgique: Bruylant, 2017. 
Nesse cenário, ao lidar com questões macros, ou seja, de vulnerabilidades que encontram explicação em estruturas fundantes dos próprios Estados, a Corte IDH não conseguirá fugir, por muito mais tempo, de temas que Ihe são tradicionalmente estranhos, tal como a função das políticas públicas estatais como forma de redução das vulnerabilidades e o quanto aquelas devem ter como uma das balizas o texto convencional. Trata-se de um caminho difícil e tortuoso, principalmente dadas as limitações convencionais existentes para o controle dos direitos sociais, bem como o risco da sua legitimidade ser forte e sistematicamente contestada.

Por outro lado, no que pese a multiplicidade de sentenças que expressamente reconhecem a vulnerabilidade, oportunidade em que instrumentalizam regras, afastam vícios procedimentais e criam critérios flexíveis de valoração probatória, não é possível concluir que a Corte conceba ou se oriente para a criação de um regime jurídico processual específico para a proteção de grupos e indivíduos vulneráveis (Capítulo 3).

Embora, em inúmeras das decisões analisadas, a Corte IDH determine, para os Estados, que a adequação procedimental é indispensável para a concretização do direito ao acesso à justiça, privilegia, para seus próprios processos, a manutenção das regras processuais vigentes e, por conseguinte, a noção clássica de equilíbrio processual entre as partes.

A Corte IDH se guia por um formalismo que vê na igualdade processual entre Estados e vítimas um corolário a ser observado. Com isso, a atuação jurisprudencial se legitima pela observância de uma ideia estreita de segurança jurídica, ao tempo em que corre o risco de esvaziar, para si própria, as noções de deveres especiais decorrentes do reconhecimento das vulnerabilidades das vítimas. Logo, apesar da notável compreensão de quem deve ser qualificado como vulnerável e do poder argumentativo que esse conceito traz em si, ainda não Ihe é conferida maiores repercussões para o processo interamericano.

A adaptação procedimental da Corte IDH, até então guiada pela cautela, não pode assentar-se apenas na igualdade processual de caráter formal, requerendo inegável esforço argumentativo em que se privilegie a necessidade de ampliação protetiva dos indivíduos e grupos vulneráveis, sob pena de esvaziamento de um ideal de justiça que se guia por um critério que se justifica pela concreta inclusão do sujeito no processo interamericano. 
Ao se deparar com demandas em que figurem indivíduos e grupos vulneráveis não se mostra suficiente, conforme se observa da jurisprudência analisada, a instrumentalidade na valoração probatória, mostrando-se imprescindível pensar na flexibilização de nulidades processuais, adequando-se in concreto o procedimento às condições pessoais e contextuais que implicaram no acionamento da justiça interamericana.

Nesse sentido, vícios processuais não podem prevalecer em relação ao direito de fundo discutido. Consoante dissertado, privar direitos pode implicar na própria desconsideração do indivíduo enquanto um sujeito de direito, negando-lhe o devido reconhecimento. Ademais, o fundamento para um comportamento processual distinto por parte dos juízes interamericanos já se encontra fartamente inscrito na jurisprudência da Corte IDH, qual seja a necessidade de as regras processuais obedecerem a critérios de justiça que levam em consideração as especificidades da vítima.

Outrossim, o uso dos contextos, enquanto elemento para fixação da prova para casos similares, embora implique o avanço significativo no âmbito interpretativo, deve caminhar ao lado de reformas que prevejam a instrumentalidade das regras processuais. Em um ideário que compreende a urgência da proteção dos vulneráveis, deve-se refletir, por exemplo, acerca da criação de procedimentos que permitam às vítimas, com direitos violados em idêntico quadro fático, se habilitarem a processos já em trâmite, dispensando-se prévia passagem perante a Comissão IDH, garantindo-se, assim, que mais indivíduos e grupos obtenham uma tutela por parte da Corte IDH.

Por fim, cabe reafirmar que o avançar implica, por conseguinte, salutar a importância da Corte IDH. Diante dos fatos recentes que convergem para o desconhecido, há que se manter as barricadas da resistência e, ao mesmo tempo, pensar em novas soluções para uma melhor concretização do Sistema Interamericano, diversas vezes o último suspiro de esperança para se alcançar o direito e a justiça. Nessa perspectiva, em que rupturas são propostas e restam acesas as fogueiras de um nacionalismo ultrapassado, mais do que precisas as palavras de Lochak, ao lembrar que "[...] l'histoire des droits de l'homme n'est ni 
l'histoire d'une marche triomphale, ni l'histoire d'une cause perdue d'avance: elle est l'histoire d'un combat's.

${ }^{5}$ LOCHAK, Danièle. Les droits de I'homme. Paris: La Découverte, 2005, p. 116. (Collection Repères). 


\section{REFERÊNCIAS BIBLIOGRÁFICAS}

ABDELGAWAD, Elisabeth Lambert; MARTIN-CHENUT, Kathia (Org.). Réparer les violations graves et massives des Droits de l'Homme: La Cour Interaméricaine, pionnière et modèle? Paris: Société de législation comparée, 2010.

ABRAMOVICH, Víctor. Das violações em massa aos padrões estruturais: novos enfoques e clássicas tensões no Sistema Interamericano de Direitos Humanos. SUR - Revista Internacional de Direitos Humanos, v. 6, n. 11, dez. 2009, p. 739. Disponível em:

https://bdjur.stj.jus.br/jspui/bitstream/2011/35351/das_violacoes_massa_abramovi ch.pdf. Acesso em: 12 set. 2018.

ACHOUR, Rafâa Ben; LAGHMANI, Slim (Dir.). Justice et juridictions internationales. Rencontres internationales de la faculté des Sciences Juridiques, Politiques et Sociales de Tunis (Colloque des 13, 14 et 15 avril 2000). Paris: Pedone, 2000.

ACCIOLY, Elizabeth (Coord.). Direito no século XXI: Em homenagem ao Professor Werter Faria. Curitiba: Juruá, 2009.

ALMEIDA, Guilherme Assis de. A proteção da pessoa humana no Direito Internacional: conflitos armados, refugiados e discriminação racial. São Paulo: Editora CLA Cultural. (E-book).

. PERRONE-MOISÉS, Cláudia (Coord.). Direito internacional dos

direitos humanos: instrumentos básicos. 2. ed. São Paulo: Atlas, 2007.

ALVARADO, Paola Andrea Acosta (Org.). Apuntes sobre el Sistema Interamericano II. Bogotá: Instituto de Estudios Constitucionales Carlos Restrepo Piedrahita, 2010.

ANDERSON, Joel; HONNETH, Axel. Autonomia, Vulnerabilidade, Reconhecimento e Justiça. Cadernos de Filosofia Alemã: Crítica e Modernidade, São Paulo, n. 17, jun. 2011. Disponível em: http://www.revistas.usp.br/filosofiaalema/article/view/64839/67456. Acesso em: 07 jul. 2017.

ANDRIANTSUMAZOVINA, J.; BURGORGUR-LARSEN, L.; TOUZÉ, S. (Org.). La protection des Droits de l'Homme par les cours supranationales (Publications de l'Institut International des Droits de l'Homme), n. 31. Paris: Pedone, 2016.

ANTKOWIAK, Thomas M; GONZA, Alejandra. The American Convention on Human Rights: essential rights. New York: Oxford University Press, 2017. 
ANSPACH, Mark Rogin. À charge de revanche: figures élémentaires de la réciprocité. Paris: Seuil, 2002.

ASSY, Bethania; MELO, Carolina de Campos et al (Org.). Direitos Humanos: justiça, verdade e memória. Rio de Janeiro: Lumen Juris, 2012.

BASSIOUNI, M. Cherif. International Recognition of Victims' Rights, p. 203-279. In: Human Rights Law Review, Oxford University Press, v. 6, n. 2, 2006.

BEDJAOUI, Mohammed. 'L'humanité En Quête de Paix et de Développement. Recueil des Cours de l'Académie de Droit International, v. 325, 2006.

BURGORGUE-LARSEN, Laurence; TORRES, Amaya Úbeda. The InterAmerican Court of Human Rights: case law and commentary. Oxford: Oxford University Press, 2011.

BURGORGUE-LARSEN, Laurence (Org.). La vulnérabilité saisie par les juges en Europe. Paris: Pedone, 2014.

. Les défis de l'interprétation et de l'application des Droits de l'Homme: de l'ouverture au dialogue. Paris: Pedone, 2017.

BROWN, Hilary. Violence against vulnerable groups. Strasbourg: Council of Europe Publishing, 2004.

BUERGENTHAL, Thomas; SHELTON, Dinah. Protection Human Rights in the Americas: Cases and Materials. 4. ed. Strasbourg: N. P. Engel Publisher, 1995.

BOBBIO, Norberto. A Era dos Direitos. Rio de Janeiro: Elsevier, 2004.

O Terceiro Ausente: ensaios e discursos sobre a paz e a guerra. São Paulo: Manole, 2009.

BOBBIO, Norberto; MATTEUCCI, N.; PASQUINO, G. Dicionário de política. Brasília: Editora Universidade de Brasília, v. 1, 1998.

CABALLERO, Susana Sanz; LLORET, Jaume Ferrer. Protection de personas y grupos vulnerables: especial referencia al Derecho Internacional y Europeu. Valencia: Tirant lo Blanc, 2008.

CARVALHO RAMOS, André de. Processo Internacional de Direitos Humanos. São Paulo: Saraiva, 2016.

CHAUVIER, Stéphane. Les principes de la justice distributive sont-ils applicable aux nations? Revue de métaphysique et de morale, n. 33, 2002, p. 123-143.

Disponível em: http://www.cairn.info/revue-de-metaphysique-et-de-morale-2002-1page-123.htm. Acesso em: 19 maio 2017.

CONTRERAS-GARDUÑO, Diana; FRASER, Julie. The identification of victims before the Inter-American Court of Human Rights and the International Criminal 
Court and its impact on participation and reparations: a domino effect? In: InterAmerican and European Human Rights Journal (Revista Interamericana y Europea de Derechos Humanos), v. 7, n. 01-02, 2014.

CORTE IDH. Exposición de Motivos de la Reforma Reglamentaria. Disponível em: http://www.corteidh.or.cr/sitios/reglamento/ene_2009_motivos_esp.pdf. Acesso em: 07 ago. 2018.

Exposición de Motivos de la Reforma Reglamentaria. Disponível em: http://www.corteidh.or.cr/sitios/reglamento/nov_2009_motivos_esp.pdf. Acesso em: 07 ago. 2018.

. Informe Anual de La Corte Interamericana de Derechos Humanos a la Asamblea General (1980). Disponível em:

http://www.corteidh.or.cr/sitios/informes/docs/SPA/spa_1980.pdf. Acesso em: 05 ago. 2018.

Regulamento da Corte Interamericana de Direitos Humanos (1980). Disponível em: http://www.corteidh.or.cr/sitios/reglamento/1980.pdf. Acesso em: 05 ago. 2018.

Regulamento da Corte Interamericana de Direitos Humanos (1991). Disponível em: http://www.corteidh.or.cr/sitios/reglamento/1991.pdf. Acesso em: 05 ago. 2018.

Regulamento da Corte Interamericana de Direitos Humanos (1996). Disponível em: http://www.corteidh.or.cr/sitios/reglamento/1996.pdf. Acesso em: 05 ago. 2018.

Regulamento da Corte Interamericana de Direitos Humanos (2000). Disponível em: http://www.corteidh.or.cr/sitios/reglamento/2000.pdf. Acesso em: 05 ago. 2018.

Regulamento da Corte Interamericana de Direitos Humanos (2009). Disponível em: http://www.corteidh.or.cr/sitios/reglamento/nov_2009_por.pdf. Acesso em: 05 ago. 2018.

Relatório Anual da Corte Interamericana de Direitos Humanos (2017). Disponível em: http://www.corteidh.or.cr/tablas/informe2017/portugues.pdf. Acesso em: 06 out. 2018.

DECAUX, E.; TOUZÉ, Sébastian (Org.). La prévention des violations des Droits de l'Homme. Actes du colloque des 13 et 14 juin 2013. Paris: Pedone, 2015.

DEGAN, Vladimir-Djuro. Création et disparition de l'État (à la lumière du démembrement de trois fédérations multiethniques en Europe). Recueil des Cours de l'Académie de Droit International, v. 279, 1999. 
DELMAS-MARTY, Mireille. Les forces imaginantes du droit II: le pluralisme ordonné. Paris: Éditions du Seuil, 2006.

. Les forces imaginantes du droit IV: vers une communauté de valeurs ? Paris: Éditions du Seuil, 2011.

. Résister, responsabiliser, anticiper ou comment humaniser la mondialisation. Paris: Seuil, 2013.

DERANTY, Jean-Philippe. Mésentente et lutte pour la reconnaissance: Honneth face à Rancière, p. 185-199. In: RENAULT, Emmanuel. Où en est la théorie critique? Paris: La Découverte, 2003.

DUGARD, John. The Secession of States and their Recognition in the Wake of Kosovo. Recueil des Cours de l'Académie de Droit International, v. 353, 2013.

DULITZKY, Ariel E.; ZARIFIS, Ismene N. Facing the challenge: the Inter-American Commission on Human Rights' adoption of new rules of procedure, p. 257-384. In: Nordic Journal of Human Rights, v. 21, 2003.

ESPIELL, Hector Gros. Le système interaméricain comme régime régional de protection internationale des droits de l'homme. Recueil des Cours de l'Académie de Droit International, v. 145, 1975.

FABRI, Hélène Ruiz ; SOREL, Jean-Marc (Org.). La preuve devant les juridictions internationales (Collection Contentieux international). Paris: Pedone, 2007.

FASSIN, Didier; RECHTMAN, Richard. The Empire of Trauma: An Inquiry into the Condition of Victimhood, Princeton, 2009.

FLAUSS, J. F. (Org.). La protection internationale des Droits de L'Homme et les Droits des Victimes (International Protection of Human Rights and Victims' Rights). Bruxelles: Bruylant, 2009. (Publications de L'Institut International des Droits de L'Homme - Institut René Cassin de Strasbourg).

FRANCK, Thomas M. The relation of justice to legitimacy in the international system. In: Humanité et Droit International: mélanges René-Jean Dupuy. Paris: Pedone, 1991.

FRASER, Nancy. Escalas de justicia. Barcelona: Herder Editorial, 2012. (Ebook).

; HONNETH, Axel. ¿Redistribución o reconocimiento? Un debate político-filosófico. Madrid: Morata, 2006.

FORST, Rainer. Justificación y crítica: perspectivas de una teoría crítica de la política. Buenos Aires: Katz Editores, 2014. 
GARAPON, Antoine. Crimes que não podemos punir nem perdoar: para uma justiça internacional. Lisboa: Instituto Piaget, 2004.

Justice et Reconnaissance. Esprit, 2006, n. 3. Disponível em:

http://www.cairn.info/revue-esprit-2006-3-page-231.htm. Acesso em: 17 maio 2017.

La justice comme reconnaissance, p. 181-204. In: CASSIN, B.; CAYALA O.; SALAZAR, P. Vérité, Réconciliation, Réparation. Paris: Seuil, 2004.

GARRAU, Marie. Politiques de la vulnérabilité. Paris: CNRS Editions, 2018.

GENEL, Katia; DERANTY, Jean-Philippe. Recognition or disagreement: a critical encounter on the politics of freedom, equality, and identity. New York: Columbia University Press, 2016.

GREIFF, Pablo de. Justiça e reparações. In: Revista Anistia Política e Justiça de Transição, n. 3, jan.-jun. 2010 - Brasília: Ministério da Justiça. Disponível em: http://www.justica.gov.br/central-deconteudo/anistia/anexos/2010revistaanistia03.pdf. Acesso em: 20 set. 2018.

GROSSMAN, Claudio; DEL CAMPO, Agustina; TRUDEAU, Mina A. International law and reparations: the Inter-American System. Atlanta (USA), 2018. (Ebook).

GROTIUS, Hugo. O direito da guerra e da paz. 2. ed. ljuí: Editora ljuí, 2005.

HENNEBEL, Ludovic. La Cour Interaméricaine des droits de l'homme: entre particularisme et universalisme. Colloque SEDI Septembre 2008. Disponível em: https://papers.ssrn.com/sol3/papers.cfm?abstract_id=2322658. Acesso em: 02 jun. 2017.

La Convention Américaine des Droits de I'Homme: mécanismes de protection et étendue des droits et libertés. Bruxelas: Bruylant, 2007.

HENNEBEL, Ludovic; TRIGOUDJA, Hélène (Org.). Le particularisme interaméricain des Droits de l'Homme. (En l'honneur du $40^{\mathrm{e}}$ anniversaire de la Convention américaine des droits de l'homme). Paris : Pedone, 2009.

2016.

. Traité de Droit International des Droits de L'Homme. Paris: Pedone,

HONNETH, Axel. Reconhecimento entre estados: sobre a base moral das relações internacionais. Civitas, v. 10, n. 1, jan.-abr. 2010, p. 134-152. Disponível em:

http://revistaseletronicas.pucrs.br/ojs/index.php/civitas/article/download/7131/516. Acesso em: 06 jun. 2017.

Crítica del Poder: Fases en la reflexión de una Teoría Crítica de la sociedad. Madrid: A. Machado Libros, 2009. E-book. 
. Rejoinder. In.: Critical Horizons, v. 16, n. 2, 2015. Disponível em: http://web.b-ebscohostcom.ez67. periodicos.capes.gov.br/ehost/pdfviewer/pdfviewer?sid=223763c9-7cf84e49-8dff-0d4b28d57b50\%40sessionmgr104\&vid=1\&hid=116. Acesso em: 04 jun. 2017.

Luta por reconhecimento: a gramática moral dos conflitos sociais. São Paulo: Editora 34, 2003.

O Direito da Liberdade. São Paulo: Martins Fontes, 2015.

Pathologies of reason: on the legacy of critical theory. New York: Columbia University Press, 2009. (E-book). Katz, 2007.

Reificación: un estudio en la teoría del reconocimiento. Buenos Aires:

A textura da justiça: sobre os limites do procedimentalismo

contemporâneo. Revista de Ciências Sociais. Porto Alegre, v. 3, n. 9, 2009.

Disponível em:

http://revistaseletronicas.pucrs.br/ojs/index.php/civitas/article/view/6896. Acesso em: 07 set. 2015.

Sofrimento de indeterminação: uma reatualização da filosofia do direito de Hegel. São Paulo: Editora Singular, Esfera Pública, 2001.

The I and We: Studies in the Theory of Recognition. Cambridge: Polity Press, 2012. E-book.

JOUANNET, E; MUIR WATT, H.; FROUVILLE, Olivier de; MATRINGE, Jean (Org.). Droit International et Reconnaissance. Paris: Pedone, 2016.

JOUANNET, E.; BURGORGUE-LARSEN, Laurence; MUIR WATT, Horatia; RUIZ FABRI, Hélène (Org.). Féminisme(s) et Droit International: études du réseau Olympe. Paris: SLC, 2016. (Collection de l'Institut des sciences juridiques et philosophique de la Sorbonne - ISJPS).

JOUANNET, E. Qu'est-ce qu'une société internationale juste? Le droit international entre développement et reconnaissance. Paris: Pedone, 2011.

. Le droit international de la reconnaissance, p. 769-793. In: Revue

Générale de Droit

International Public. Paris: Pedone, Tomo CXVI, 2012, n. 04.

KELSEN, Hans. A paz pelo direito. São Paulo: Martins Fontes, 2011.

LAFER, Celso. A Reconstrução dos Direitos Humanos: um diálogo com o pensamento de Hannah Arendt. São Paulo: Companhia das Letras, 1988. 
LOCHAK, Danièle. Les droits de l'homme. Paris: La Découverte, 2005. (Collection Repères).

LAGARDE, Paul. La méthode de la reconnaissance est-elle l'avenir du droit international privé? Conférence inaugurale, session de droit international privé. Recueil des Cours de l'Académie de Droit International, v. 371, 2014.

LAVRYSEN, Laurens. Positive obligations in the jurisprudence of the InterAmerican Court of Human Rights. In: Inter-American and European Human Rights Journal (Revista Interamericana y Europea de Derechos Humanos), v. 7, n. 1-2, 2014.

LE FUR, Louis. Précis de droit international. Paris: Librairie Dalloz, 1933.

LEMASSON, Aurélien-Thibaut. La victime devant la justice pénale internationale: pour une action civile internationale. Limoges: Pulim, 2012

LOPES, José Reinaldo de Lima. As palavras e a lei: direito, ordem e justiça na história do pensamento jurídico moderno. São Paulo: Editora 34/Edesp. 2004.

MAILLARD, Nathalie. La vulnérabilité: une nouvelle catégorie morale? Genebra: Labor et Fides, 2011.

MANDELSTAM, André. La protection des Minorités. Recueil des Cours de l'Académie de Droit International, v. 01, 1923.

MAZZESCHI, Riccardo Pisillo. Responsabilité de l'État pour violation des obligations positives relatives aux Droits de l'Homme. Recueil des Cours de l'Académie de Droit International, v. 333, 2008.

MCNEILL, David N. Social freedom and self-actualization normative reconstruction as a Theory of Justice. In: Critical Horizons: A Journal of Philosophy and Social Theory, v. 16, n. 2, 2015. Disponível em: http://dx.doi.org/10.1179/1440991715Z.00000000045. Acesso em: 03 jun. 2017.

MEDINA, Cecilia. The American Convention on the Human Rights: crucial rights and their theory and practice. Cambridge: Intersentia, 2014.

MELO, Rúrion (Org.). A teoria crítica de Axel Honneth: reconhecimento, liberdade e justiça. Saraiva: São Paulo, 2013. (E-book).

NAÇÕES UNIDAS. Carta das Nações Unidas e Estatuto da Corte Internacional de Justiça. Disponível em:

http://unicrio.org.br/img/CartadaONU_Versolnternet.pdf. Acesso em: 08 fev. 2017.

NIFOSI-SUTTON, Ingrid. The Protection of Vulnerable Groups under International Human Rights Law. NY: Routledge, 2017.

OEA. Ata Final da Quinta Reunião de Consulta de Ministros de Relações Exteriores (1949). Disponível em: 
http://www.oas.org/es/cidh/mandato/Basicos/Acta-final-Quinta-reunion-Chile1959.pdf. Acesso em: 24 jun. 2018.

Convenção Interamericana contra toda forma de discriminação e intolerância. Disponível em: https://www.oas.org/en/sla/dil/docs/inter_american_treaties_A69_Convencao_Interamericana_disciminacao_intolerancia_POR.pdf. Acesso em: 08 ago. 2018.

Regulamento da Corte Interamericana de Direitos Humanos sobre o funcionamento do fundo de assistência jurídica às vítimas. Disponível em: https://www.oas.org/pt/cidh/mandato/Basicos/asistenciaCorte.pdf. Acesso em: 20 nov. 2018.

Resolução XXII - Ampliação das Faculdades da Comissão Interamericana de Direitos Humanos - $2^{a}$ Conferência Interamericana Extraordinária - RJ -1965. Ata Final da Segunda Conferência.

ONUMA, Yasuaki. Direito internacional em perspectiva transcivilizacional: questionamento da estrutura cognitiva predominante no emergente mundo multipolar e multicivilizacional do século XXI. Belo Horizonte: Arraes Editores, 2017.

OSMO, Carla; MARTIN-CHENUT, Kathia. A participação das vítimas no sistema interamericano: fundamento e significado do direito de participar. In: Revista Direito \& Práxis, Rio de Janeiro, v. 8, n. 2, p. 1455-1506. Disponível em: http://www.epublicacoes.uerj.br/index.php/revistaceaju/article/download/28031/20620. Acesso em: 22 jun. 2017.

OST, François. À quoi sert le droit ? Usages, fonctions, finalités. Bruxelas: Bruylant, 2016.

A tese de doutorado em Direito: do projeto à defesa. Revista de Estudos Constitucionais, Hermenêutica e Teoria do Direito (RECHTD), maioago. 2015. Disponível em:

http://revistas.unisinos.br/index.php/RECHTD/article/view/rechtd.2015.72.01/4718. Acesso em: 05 jul. 2017.

PASQUALUCCI, JO M. The practice and procedure of the Inter-American Court of Human Rights. 2. ed. New York, NY: Cambridge University Press, 2013.

PERRONE-MOISÉS, Cláudia. Direito ao desenvolvimento e investimentos estrangeiros. São Paulo: Editora Mendes, 1998.

2012.

. Direito Internacional Penal: Imunidades e Anistias. São Paulo: Manole,

PUFENDORF, Samuel. Os Deveres do Homem e do Cidadão de acordo com as Leis do Direito Natural. Rio de Janeiro: Topbooks, 2007. 
QUIÑONES, Paola Pelletier. La "discriminación estructural" en la evolución jurisprudencial de la Corte Interamericana de Derechos Humanos. In: Revista del Instituto Interamericano de Derechos Humanos, n. 60, julio-diciembre 2014.

RAMA-MONTALDO, Manuel. La codification du droit international comme instrument de la justice internationale. Les Cahiers de droit, v. 42, n. 3, 2001, p. 711-723.

RAWLS, John. Justicia como equidad: materiales para una teoría de la justicia. Madrid: Tecnos, 2013

RENAULT, Emmanuel. L'expérience de l'injustice: essai sur la théorie de la reconnaissance. Paris: La Découverte, 2017.

RICOEUR, Paul. Amor e justiça. São Paulo: Martins Fontes, 2012.

. O justo 1: a justiça como regra moral e como instituição. São Paulo: Martins Fontes, 2008.

2008.

. O justo 2: justiça e verdade e outros estudos. São Paulo: Martins Fontes,

. Percurso do reconhecimento. São Paulo: Edições Loyola, 2006.

Soi-même comme un autre. Paris: Éditions du Seuil, 1990.

Tempo e narrativa. Tomo I. Campinas, SP: Papirus, 2009.

RIVIĖRE, Florence. Les opinions séparées des juges à la Cour Européenne des Droits de I'Homme. Bruxelas: Bruylant, 2005, 464 p.

ROMANI, Carlos Ferrnandez de Casadevante. International Law of Victims. Canadá: Springer, 2012. (E-book).

ROOSMANLEN, Marjolein van; VERMEULEN, Ben; HOOF, Fried van; OOSTING, Marten (Org.). Fundamental Rights and Principles (liber amicorum Pieter van Dijk). Cambridge: Intersentia, 2013.

ROTA, Marie. L'interprétation des Coventions Américaine et Européene des Droits de I'Homme: analyse comparée de la jurisprudence des Cours Européenne et Interaméricaine des Droits de l'Homme. Issy-les-Moulineaux: LGDJ, 2018.

ROUSSEAU, Charles. Le droit international et l'idée de justice, p. 399-403. In: Le droit international au service de la paix, de la justice et du développement: mélanges Michel Virally. Paris: Pédone, 1991. 
RUET, Céline. Sentiments et droits de l'homme: philosophie des sentiments moraux et jurisprudence de la Cour euroéenne des droits de l'homme, p. 351-379. In: Revue Trimestrielle des Droits de I'Homme, n. 105, jan. 2016.

SAAVEDRA, Giovani A.; SOBOTTKA, Emil A. Introdução à teoria do reconhecimento de Axel Honneth. Porto Alegre: Civitas, v. 8, n. 01, p. 9-19, jan.abr. 2008. Disponível em:

http://revistaseletronicas.pucrs.br/ojs/index.php/civitas/article/view/4319. Acesso em: 20 set. 2015.

SARTI, Cynthia. A vítima como figura contemporânea. Cadernos CRH, Salvador, v. 24, n. 61,2011 , p. 51-61.

SCHAHMANECHE, Aurélia. La Cour européenne des droits de l'homme, nouveau pouvoir, p. 33-56. In: CAIRE, Anne-Blandine (Coord.). Les nouveaux pouvoirs: approche pluraliste des foyers de création du droit. Belgique: Bruylant, 2017.

SCHLEGEL, Jean-Louis. Les institutions, entre le juste et le bon. In: Paul Ricoeur, penser des institutions justes. Esprit, 2017, n. 439.

SCHRAMM, Luanda. Reconhecimento, justiça e despolitização da teoria política contemporânea. Aracê - Direitos Humanos em Revista, v. 1, n. 1, 2014.

SHAW, Malcolm N. Direito Internacional. São Paulo: Martins Fontes, 2010.

SIMIM, Thiago A. A justiça das instituições sociais. Porto Alegre: Civitas, v. 15, n. 4, p. 648-663, out.-dez. 2015. Disponível em:

http://revistaseletronicas.pucrs.br/ojs/index.php/civitas/article/download/20526/141 13. Acesso em: 18 fev. 2017.

SIJNIENSKY, Romina I. From the non-discrimination clause to the concept of vulnerability in international human rights law, p. 259- 272. In: HAECK, Yves et al (Org.). The realization of human rights: when theory meets practice. Studies in honour of Leo Zwaak. Cambridge: Intersentia, 2013.

TAYLOR, Charles. Argumentos filosóficos. 2. ed. São Paulo: Loyola, 2014.

Multiculturalismo: examinando a política de reconhecimento. Lisboa: Instituto Piaget, 1998.

TIMMER, Alexandra. A quiet revolution: vulnerability in the European Court of Human Rights, p. 147-170. In: FINEMAN, M.; GREAR, A. (Org.). Vulnerability: reflections on a new ethical foundation for law and politics. Farnham: Ashgate, 2013.

TOUZÉ, Sébastien. Les techniques interprétatives des organes de protection des droits de l'homme, p. 517-532. In: Revue Genérale de Droit International Public (RGDIP). Paris: Pedone, tomo 115, n. 2, 2011. 
TRIBUNAL PENAL INTERNACIONAL. ICC-01/04-01/07. Affaire Le Procureur vs. Germain Katanga (Situation en République Démocratique du Congo). Ordonnance de Réparation, de 24 de mar. 2017. Disponível em: https://www.icccpi.int/CourtRecords/CR2017_01525.PDF. Acesso em: 31 ago. 2018.

TRINDADE, A. A. C. A humanização do Direito Internacional. 2. ed. Belo Horizonte: Del Rey, 2015.

A proteção dos vulneráveis como legado da II Conferência Mundial de Direitos Humanos (1993-2013). Fortaleza: IBDH/IIDH/SLADI, 2014.

Tratado de Direito Internacional dos Direitos Humanos. Porto Alegre: Sergio Antonio Fabris Editor, 2003, v. 3.

VASAK, Karel. La Comission Interaméricaine des Droits de I'Homme. Paris: Librairie Générale de Droit et de Jurisprudence, 1968.

VATTEL, Emer de. O direito das gentes. Brasília: Editora Universidade de Brasília - IPRI, 2004.

VILMER, Jean-Baptiste Jeangène. Réparer l'irréparable: les réparations aux victimes devant la Cour Pénale Internationale. Paris: PUF, 2009.

VITA, Álvaro de. O liberalismo igualitário: sociedade democrática e justiça internacional. São Paulo: WMF Martins Fontes, 2008.

\section{CASOS DA CORTE IDH}

CORTE INTERAMERICANA DE DIREITOS HUMANOS. Caso Artavia Murillo e outros vs. Costa Rica. Sentença de 28 set. 2012. Disponível em:

http://www.corteidh.or.cr/docs/casos/articulos/seriec_257_por.pdf. Acesso em: 09 jul. 2017.

Caso Atala Riffo e crianças vs. Chile. Sentença de 07 julho 2011.

Disponível em: http://www.corteidh.or.cr/docs/casos/articulos/seriec_254_esp.pdf. Acesso em: 09 jul. 2017.

Caso Bámaca Velásquez vs. Guatemala. Sentença de 25 nov. 2000. Disponível em: http://www.corteidh.or.cr/docs/casos/articulos/Seriec_70_esp.pdf. Acesso em: 09 jul. 2017.

Caso Comunidades Afrodescendentes deslocados da Bacia do Rio Cacarica (Operação Gênesis) vs. Colômbia. Sentença de 20 nov. 2013.

Disponível em: http://www.corteidh.or.cr/docs/casos/articulos/seriec_270_esp.pdf. Acesso em: 09 jul. 2017.

. Caso Comunidade Indígena Yakye Axa vs. Paraguai. Sentença de 17 jun. 2005. Disponível em: 
http://www.corteidh.or.cr/docs/casos/articulos/seriec_125_esp.pdf. Acesso em: 09 jul. 2017.

. Caso Comunidade Mayagna (Sumo) Awas Tingni vs. Nicarágua.

Sentença de 31 ago. 2001. Disponível em:

http://www.corteidh.or.cr/docs/casos/articulos/Seriec_79_esp.pdf. Acesso em: 09 jul. 2017.

Caso Comunidade Moiwana vs. Suriname. Sentença de 15 jun. 2005. Disponível em: http://www.corteidh.or.cr/docs/casos/articulos/seriec_1_esp.pdf. Acesso em: 09 jul. 2017.

. Caso das Meninas Yean e Bosico vs. Republica Dominicana.

Sentença de 23 nov. 2006. Disponível em:

http://www.corteidh.or.cr/docs/casos/articulos/seriec_156_esp.pdf. Acesso em: 09 jul. 2017.

Caso das pessoas dominicanas e haitianas expulsas vs. República Dominicana. Sentença de 28 ago. 2014. Disponível em: http://corteidh.or.cr/docs/casos/articulos/seriec_282_esp.pdf. Acesso em: 09 jul. 2017.

. Caso do Povo Indígena Xucuru e seus membros vs. Brasil. Sentença de 05 fev. $2018 . \quad$ Disponível em: http://www.corteidh.or.cr/docs/casos/articulos/seriec_346_por.pdf. Acesso em: 09 maio 2018.

Caso do Povo Saramaka vs. Suriname. Sentença de 28 nov. 2007. Disponível em: http://www.corteidh.or.cr/docs/casos/articulos/seriec_172_esp.pdf. Acesso em: 09 jul. 2017.

Caso do Presídio Miguel Castro Castro vs. Peru. Sentença de 25 nov. 2006. Disponível em:

http://www.corteidh.or.cr/docs/casos/articulos/seriec_160_por.doc. Acesso em: 09 jul. 2017.

Caso Duque vs. Colômbia. Sentença de 21 nov. 2016. Disponível em: http://www.corteidh.or.cr/docs/casos/articulos/seriec_310_esp.pdf. Acesso em: 09 jul. 2017.

Caso Espinoza Gonzáles vs. Peru. Sentença de 20 nov. 2015.

Disponível em: http://www.corteidh.or.cr/docs/casos/articulos/seriec_289_esp.pdf. Acesso em: 09 jul. 2017. - contexto -\$67

Caso Família Pacheco Tineo vs. Bolívia. Sentença de 25 nov. 2013. Disponível em: http://www.corteidh.or.cr/docs/casos/articulos/seriec_272_esp.pdf. Acesso em: 09 jul. 2017. 
. Caso Flor Freire vs. Equador. Sentença de 31 ago. 2016. Disponível em: http://www.corteidh.or.cr/docs/casos/articulos/seriec_315_esp.pdf. Acesso em: 09 jul. 2017.

Caso Furlán e familiares vs. Argentina. Sentença de 31 ago. 2012. Disponível em: http://www.corteidh.or.cr/docs/casos/articulos/seriec_246_esp.pdf. Acesso em: 09 jul. 2017.

. Caso Gomes Lund e outros ("Guerrilha do Araguaia”) vs. Brasil. Sentença de 24 nov. 2010. Disponível em: http://www.corteidh.or.cr/docs/casos/articulos/seriec_219_por.pdf. Acesso em: 10 abr. 2018.

. Caso González e outros vs. México. Sentença de 16 nov. 2009.

Disponível em: http://www.corteidh.or.cr/docs/casos/articulos/seriec_205_por.pdf. Acesso em: 09 jul. 2017.

Caso Gonzales Lluy e outros vs. Equador. Sentença de 01 set. 2015. Disponível em: http://www.corteidh.or.cr/docs/casos/articulos/seriec_298_esp.pdf. Acesso em: 09 jul. 2017.

. Caso "Instituto de Reeducação do Menor" vs. Paraguai. Sentença de 02 de set. 2004. Disponível em:

http://www.corteidh.or.cr/docs/casos/articulos/seriec_112_esp.pdf. Acesso em: 09 jul. 2017.

Caso J. vs. Peru. Sentença de 27 nov. 2013. Disponível em:

http://www.corteidh.or.cr/docs/casos/articulos/seriec_275_esp.pdf. Acesso em: 09 jul. 2017.

Caso Lagos del Campo vs. Perú. Sentença de 31 ago. 2017.

Disponível em: http://www.corteidh.or.cr/docs/casos/articulos/seriec_340_esp.pdf. Acesso em: 10 abr. 2018.

. Caso Loayza Tamayo vs. Peru. Sentença de 17 set. 1997. Disponível em: http://www.corteidh.or.cr/docs/casos/articulos/seriec_33_esp.pdf. Acesso em: 09 jul. 2017.

Caso Nadege Dorzema e outros vs. República Dominicana. Sentença de 24 ago. 2012. Disponível em:

http://www.corteidh.or.cr/docs/casos/articulos/seriec_251_por.pdf. Acesso em: 09 jul. 2017.

. Caso Povo Indígena Kichwa Sarayaku vs. Equador. Sentença de 27 jun. 2012. Disponível em: http://www.corteidh.or.cr/docs/casos/articulos/seriec_245_esp.pdf. Acesso em: 09 jul. 2017. 
2015. Disponível em:

. Caso Povos Kaliña e Lokono vs. Suriname. Sentença de 25 nov. http://www.corteidh.or.cr/docs/casos/articulos/seriec_309_esp.pdf. Acesso em: 09 jul. 2017.

Caso Trabalhadores da Fazenda Brasil Verde vs. Brasil. Sentença de 20 out. 2016. Disponível em:

http://www.corteidh.or.cr/docs/casos/articulos/seriec_318_por.pdf. Acesso em: 09 jul. 2017.

Caso Velásquez Paiz e outros vs. Guatemala. Sentença de 19 nov. 2015. Disponível em:

http://www.corteidh.or.cr/docs/casos/articulos/seriec_307_esp.pdf. Acesso em: 09 jul. 2017.

Caso Velásquez Rodrigues vs. Honduras. Sentença de 29 jul. 1988. Disponível em: http://www.corteidh.or.cr/docs/casos/articulos/seriec_04_por.doc. Acesso em: 09 jul. 2017.

. Caso Vélez Loor vs. Panamá. Sentença de 23 nov. 2010. Disponível em: http://www.corteidh.or.cr/docs/casos/articulos/seriec_218_esp2.pdf. Acesso em: 09 jul. 2017.

Caso Vereda La Esperanza vs. Colombia. Sentença de 31 ago. 2017. Disponível em: http://www.corteidh.or.cr/docs/casos/articulos/seriec_341_esp.pdf. Acesso em: 10 abr. 2018.

Caso Villagrán Morales e outros vs. Guatemala. Sentença de 17 nov. 1999. Disponível em: http://www.corteidh.or.cr/docs/casos/articulos/Seriec_63_esp.pdf. Acesso em: 09 jul. 2017.

. Caso Ximenes Lopes vs. Brasil. Sentença de 04 julho 2006. Disponível em: http://www.corteidh.or.cr/docs/casos/articulos/seriec_149_por.pdf. Acesso em: 09 jul. 2017.

. Caso Wong Ho Wing vs. Peru. Sentença de 30 jun. 2015. Disponível em: http://www.corteidh.or.cr/docs/casos/articulos/seriec_297_esp.pdf. Acesso em: 09 jul. 2017.

Condição Jurídica e Direitos dos Migrantes Indocumentados.

Opinião Consultiva n. 18 de 17 set. 2003. Disponível em:

http://www.corteidh.or.cr/docs/opiniones/seriea_18_esp.pdf. Acesso em: 09 jul. 2017.

Direitos e garantias dos meninos e meninas no contexto da migração e ou a necessidade de proteção internacional. Opinião Consultiva $\mathrm{n}$. 21 de 19 ago. 2014. Disponível em: http://www.corteidh.or.cr/docs/opiniones/seriea_21_esp.pdf. Acesso em: 09 jul. 2017. 
Identidade de gênero, igualdade e não discriminação entre casais do mesmo sexo. Opinião Consultiva n. 24, de 24 nov. 2017. Disponível em: http://www.corteidh.or.cr/docs/opiniones/seriea_24_esp.pdf. Acesso em: 15 mar. 2018.

Proposta de modificação da Constituição Política da Costa Rica relacionada a naturalização. Opinião Consultiva n. 4 de 19 jan. 1984. Disponível em: http://www.corteidh.or.cr/docs/opiniones/seriea_04_esp.pdf. Acesso em: 09 jul. 2017. 